\title{
Exposições de Dinossauros em Portugal Comunicar Paleontologia, Métodos e Problemáticas
}

\author{
Simão Mateus \\ Museu da Lourinhã \\ E-mail: simaomateus@rocketmail.com
}

\begin{abstract}
Resumo
Portugal tem diversos museus com exposições de paleontologia que abordam a temática dos dinossauros, alguns já expondo esqueletos completos em forma de vida nas suas colecções permanentes. $\mathrm{O}$ aparecimento deste género de exposições desde os anos oitenta tem acompanhado a crescente procura por este produto, mas será que tem acompanhado as expectativas? Como é que o público percepciona os dinossauros? Como fonte de deslumbramento e entretenimento do público in-

fantil? Como colecção de esqueletos de um museu de história natural? Como resultado de uma investigação científica complexa? Pretende-se fazer o levantamento de algumas exposições com dinossauros de Portugal, caracterizar a tipologia de discurso expositivo, a metodologia aplicada e as suas debilidades. Os diversos museus, ou congéneres equivalentes, foram visitados ao longo dos últimos anos, e feito uma análise às suas exposições.
\end{abstract}

Palavras Chave: Exposição de Dinossauros; Paleontologia; Museus Portugueses; Fósseis; Réplicas.

\begin{abstract}
Portugal has several museums with paleontology exhibitions that showcase dinosaurs, some with complete skeletons in lifelike positions in their permanent collections. Since the 1980s, this type of exhibition has met the rise in public demand, but has it also met its expectations? How does the public perceive dinosaurs? As a source of wonder and entertainment for children? As part of the skeleton col-

lection from a natural history museum? As the result of complex scientific research? This article will present a survey of some of the dinosaur exhibitions in Portugal, characterizing the type of exhibition, the metholodogy that was applied and it's frailties. Various museums, or similar entities, were visited over the past few years and their exhibits were analyzed.
\end{abstract}


Key-words: Dinosaurs exhibitions; Paleontology; Portuguese Museums; Fossils;

Casts.

\section{Introdução}

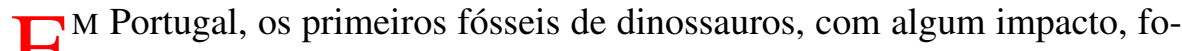

C ram expostos no início da segunda metade do século XX, no Museu Geológico e Mineiro de Lisboa, nomeadamente os grandes saurópodes denominados por Lapparent e Zbyszewski (1957) como o Brachiosaurus atalaiensis ou o Apatosaurus alenquerensis, actualmente os géneros Lusotitan e Lourinhasaurus respectivamente.

Nos anos oitenta, com o crescimento do número de museus em Portugal, aqueles em regiões fossilíferas, nomeadamente Mesozóicas, começaram a expor fósseis de grandes vertebrados. O uso dos fósseis em exposição vai desde a curiosidade geológica, herdado dos gabinetes de curiosidades, ao afirmar da relevância histórica de um dado concelho (Mateus, 2014). Os museus da zona Oeste não passaram ao lado desta tendência e, mais ou menos cientificamente, começaram a expor o seu património paleontológico. Hoje já existem diversos museus com exposições de dinossauros, alguns com esqueletos completos em forma de vida nas suas colecções permanentes.

Se, nos anos oitenta, a única forma de observar um esqueleto de dinossauro montado em forma de vida era viajando até aos museus de história natural internacionais, como o de Paris, Londres ou Berlim, com o advento das exposições temáticas, do início dos anos 90, passou a ser possível fazer a sua visualização também em Portugal, pelo menos temporariamente. Só em 2007 é que Portugal passou a contar com esqueletos completos nas suas exposições permanentes, nomeadamente os dinossauros portugueses, Lourinhanosaurus antunesi e o Miragaia longicollum no Museu da Lourinhã.

Este museu é, aliás, um caso particular. Foi inaugurado em 1984, e encontrou nos dinossauros o seu carácter de unicidade, com salas de exposição inteiramente dedicadas a estes animais e outros répteis mesozóicos, e que levou a vila a ser conhecida como a Capital dos Dinossauros.

Mas será que este género de exposições serve o propósito da comunicação científica, a comunicação da paleontologia? 
Exposições de Dinossauros em Portugal: Comunicar Paleontologia, Métodos e Problemáticas

Os museus podem ter objectivos conflituosos: de investigação científica, educação do público, e entretenimento da população. Um tema que atraia as audiências é tão importante para entretenimento do público como para financiamento do museu. (Rieppel, 2012: 460).

No caso Português a maioria dos museus não desempenha um papel significativo no campo da investigação cienífica, existindo porém algumas excepções (Delicado, 2008: 69). A maioria dos museu portugueses tem mais preocupações com a educação do público, enquanto que as exposições temporárias com dinossauros servem principalmente de entretenimento, nomeadamente infantil.

\section{Dinossauros e os objectivos museológicos}

Shmuel Meiri (2004) expõe na sua tese The museology of dinosaurs: in search of the authentic museum dinosaur, a história da museologia de dinossauros e a problemática da autenticidade e papel educativo dos objectos expostos. No caso dos dinossauros, vai uma grande distância da exposição de investigação paleontológica, pura, passando pela exibição de esqueletos montados, até ao aparecimento de modelos flesh-out, i.e., com reconstituição das partes moles, como se estivessem vivos (Figura 1).

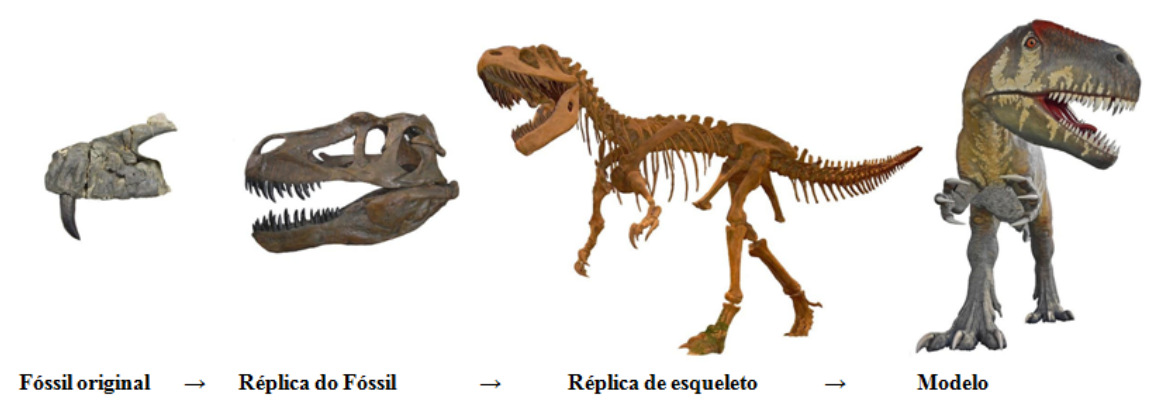

Figura 1 - Torvosaurus gurney, diversos aspectos (Fóssil ML1100; Réplica de crânio do Museu da Lourinhã; Esqueleto de Torvosaurus tanneri, do North American Museum of Ancient Life, fonte Wikimedia Commons; Modelo do Dinosaurier-park Münchehagen) 
Para a investigação científica dos paleontólogos praticamente só os fósseis contam, independentemente do grau de completude e estética inerente ao próprio fóssil. Mas frequentemente esse fóssil é de dificil interpretação para um leigo, ou seja, a maioria do público.

Já a presença de um esqueleto montado em forma de vida permite uma leitura quase universal. Os esqueletos em posição de vida têm uma legibilidade mais rápida e fácil que um esqueleto original e parcial, sendo as réplicas mais atractivas ao grande público (Mateus, 2009).

A montagem de um esqueleto passa por uma série de interpretações que, pretendendo ser o mais correctas possíveis, são, ainda assim, permeáveis a erros (Meiri, 2004).

A larga maioria dos dinossauros é descoberta com menos de metade do esqueleto. A parte em falta pode ser colmatada de diversas formas: i) por simetria bilateral (p.e.: com o membro direito reproduz-se o esquerdo); ii) com outros esqueletos de animais da mesma espécie (casos raros); iii) com as espécies mais próximas possíveis (sister clade); iv) por escultura interpretativa (p.e.: faltando vértebras, esculpem-se as falhas tendo em atenção a morfologia das vértebras adjacentes. Todos estes métodos visam o aumento interpretativo de um fóssil, mas elevam a possibilidade de erro inerente da interpretação. São estes a maioria dos objectos que o público observa em exposições com dinossauros.

Além da contemplação, a presença de réplicas de dinossauros numa exposição pode servir como elementos interpretativos de originais que disso necessitem, quer por questões de dimensão como por questões de facilitador de compreensão, ou servirem como cópias de segurança, divulgação e duplicação, marketing e produto financeiro (Mateus, 2009).

Quando se passa à reconstituição de um animal com partes moles, com "pele", a interpretação aumenta e, com ela, a margem de erro. O caso clássico de interpretação máxima é a cor atribuida aos animais, que é desconhecida e fica ao critério estético do paleoartista, não tendo qualquer critério científico. Este é o caso da maioria dos parques temáticos com dinossauros.

Assim vemos uma progressão que vai entre o científico e o lúdico e que acompanha a progressão que vai desde o fóssil ao modelo, a investigação ao entretenimento. (figura 2) 


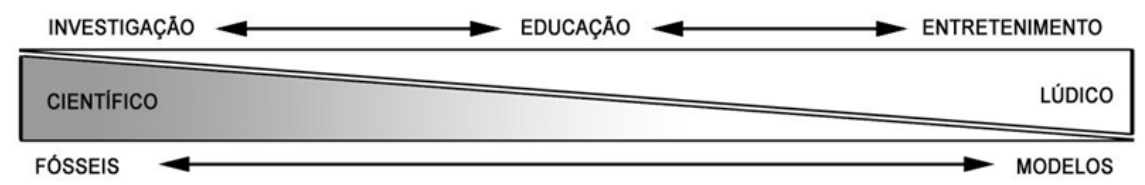

Figura 2 - Diagrama interpretativo de fósseis a modelos

Em certos aspectos esta progressão parece estar intimamente ligada à idade do público alvo, ou, pelo menos, à tipologia deste. Fósseis são procurados por público científico, investigadores e universitários. Esqueletos para um público mais generalista aberto às ciências naturais, e quando falamos de parques temáticos, quase sempre as actividades estão direccionadas para o público infantil. Quando se visita um parque temático de dinossauros, sem se levar crianças, existe frequentemente um sentimento de não pertença, de, enquanto adultos, sentirmo-nos deslocados. As atracções, interpretações, os espaços de descanso e mesmo os menus da cafetaria são viradas principalmente para as crianças. O exemplo mais próximo é o caso de Dinópolis, em Teruel, Espanha.

Esta orientação museográfica não tem que ser necessariamente dirigida ao público infantil, mas a realidade é que esses parques são geridos tendo em vista as famílias com filhos pequenos. A exposição visa a satisfação da criança, enquanto produtor de sentimento de aventura de "Parque Jurássico", e os adultos como produtor de sentimento de tempo de qualidade com as crianças mais do que como promotor de divulgação científica.

Por outro lado, é inegável o papel do entretenimento infantil como substancial fonte de financiamento para a gestão diária e manutenção dos parques e museus e que, indirectamente suportam parte da investigação científica.

\section{Exposições de Dinossauros em Portugal}

Portugal teve fósseis de dinossauros em exposição desde a segunda metade do século XX, nomeadamente no Museu Geológico e Mineiro, em Lisboa, resultantes das expedições das comissões geológicas. A exposição de 
esqueletos completos só se deu no final do século XX e sob a forma de exposições temporárias ${ }^{1}$.

A primeira exposição de dinossauros em Portugal, com grande impacto no público, ocorreu em 1992/1993 no Museu Nacional de História Natural e da Ciência (MUHNAC) com esqueletos completos e dinossauros robotizados. A exposição denominava-se "Dinossaurios Regressam a Lisboa" com uma afluência recorde de 350 mil visitantes (Leite, 2009: 33). No ano seguinte foi a vez da exposição "Dinossauros ao vivo" no Jardim Zoológico de Lisboa.

O sucesso das duas primeiras exposições temporárias, do Museu de História Natural e do Jardim Zoológico, ambas em Lisboa, com esqueletos completos e dinossauros robotizados, mostrou a apetência que o público tinha por esta temática. Público esse que tinha, e tem, nas crianças o seu motor.

Estas exposições têm como aliado o filme de Steven Spielberg, Jurassic Park, que em 1993 vem fomentar a procura dos dinossauros num fenómeno que ficou conhecido por "dinomania", numa explosão de popularidade destes animais (Meiri, 2004; Mitchell, 1998).

Já no século XXI começam a ser mais comuns as exposições temáticas com esqueletos completos e nos últimos anos aparecem à razão de uma por ano. A descoberta da característica lucrativa dos dinossauros, que começam também a ter preços mais em conta, nem sempre gera exposições de qualidade científica. Um exemplo negativo foi a série de do "Mundo dos dinossauros" que começa em 2011 na cordoaria nacional, com um rigor científico duvidoso, havendo dioramas com encontros de animais de Eras diferentes, pterossauros montados de braços ao contrário e posteres informativos que surgiam de más traduções de livros, com palavras da mesma frase em três línguas e o poster a acabar em rodapé "como se vê na próxima página". As megas exposições de dinossauros começam a ser utilizadas principalmente como máquinas de fazer dinheiro.

Um caso de comunicação de paleontologia diferente foi a do espetáculo Walking With Dinosaurs, em Lisboa, no Pavilhão Atlantico, 14 e 16 de Maio de 2010. O espetáculo continha robôs manipulados por operadores que interagiam com um actor (Paulo Matos) que desempenhava o papel de paleontólogo.

1. Ver em anexo a cronologia das principais exposições temáticas de dinossauros em Portugal. 
Exposições de Dinossauros em Portugal: Comunicar Paleontologia, Métodos e Problemáticas

Neste espetáculo não existem fósseis, réplicas ou modelos para se visitar, e por isso não pode ser considerado uma exposição museológica.

\section{Comunicar paleontologia e o léxico científico: O exemplo de "Aves"}

Assim como o uso de fósseis, sem alterações interpretativas, o uso de modelos tem uma progressão do mais científico para o mais lúdico, a terminologia usada no acompanhamento do discurso expositivo também possui idêntica progressão, indo da mais científica e menos perceptível à maioria do público, para a mais popular e compreensível, mas mais aberta a erros (figura 3). Quanto mais público se pretende alcançar menos conceitos se pode exigir. Ainda por cima quando o público é constituido por crianças a nível do primeiro ciclo escolar (Mateus et al., 2014).

Conceitos como eras e períodos, género e espécie, holótipo e autapomorfia, fundamentais na linguagem palontológica e pertencem ao léxico da literatura científica, são expressões vagas, ou mesmo inexistentes, para o público leigo.

Os paleontólogos necessitam de usar critérios taxonómicos como autoridade científica para dar significado a nomes e um dos casos clássicos é a propriedade da palavra "aves". Qualquer pessoa consegue perceber o que é uma ave e esta palavra, e o seu conceito, é muito anterior à de dinossauros.

No entanto, paleontologicamente o significado de ave não é assim tão claro. A comunidade científica teve dificuldade em definir apartir do momento em que um dinossauro era considerado uma ave: i) tinha penas; ii) voava; iii) os descendentes do Archaeopteryx; ou, iv) eram os descendentes vivos que resultam de iii e são somente as aves actuais (Gauthier e Queiroz, 2001: 8).

Independentemente do que são, a compreensão do público de uma exposição do que é uma ave dificilmente coincidirá com a do paleontólogo.

A equipa museográfica não deve presumir o conhecimento de conceitos complexos por parte do público e os cientistas devem acautelar a arrogância de achar que o seu léxico é o detentor de toda a verdade científica e a humildade de ceder em precisão científica alcançando porém maior compreensibilidade. 


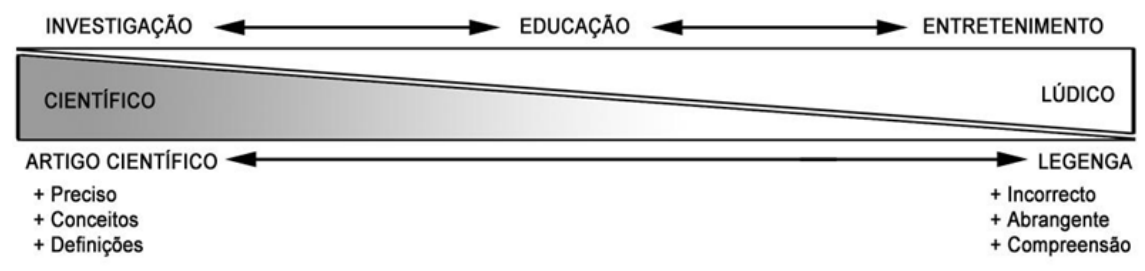

Figura 3 - Diagrama interpretativo do léxico dos artigos científicos às legendas museológicas

\section{Dilema cognitivo}

As crianças em idade pré-escolar começam a aprender o nome dos dinossauros, com alguma facilidade. Sabem o nome dos dinossauros mas ainda não conseguem relacioná-los com aspectos mais abstractos como eras e períodos, taxonomia e evolução, só conseguindo apreender os conceitos abstratos como o que é um dinossauro ou o tempo geológico mais para o final do ensino básico (Barba, 1995). Não obstante, existe uma procura por parte dos tutores de introduzir estes conceitos complexos às crianças mais pequenas. A maioria dos museus e exposições de dinossauros não estão preparados para a transmissão dessa informação, nem através dos textos nem do discurso expositivo. A fim de colmatar esta stuação, em alguns casos recorrem-se aos serviços educativos e às visitas guiadas. No caso da comunicação da paleontologia pode não ser simples. As crianças têm falta de capacidade de concentração para ter uma explicação muito longa e facilmente perdem o interesse.

Um caso particular ilustra a problemática da comunicação da paleontologia: Um casal com uma criança de cinco anos pede uma visita guiada. $\mathrm{O}$ guia, mestre em paleontologia, tenta fazer uma introdução básica ao tema sendo interrompido pelos pais com o pedido: «Não fale para nós (adultos) fale para ele (criança)!». A explicação dos conceitos básicos da paleontologia fica assim limitada à capacidade de aquisição de conhecimentos de uma criança de cinco anos, que regra geral sabem o nome de alguns dinossauros, e associam herbívoros como "bons", e carnívoros como "maus". Quais os dinossauros que, por exemplo, existiam no Jurássico e em Portugal é praticamente impossível de passar. 
A afirmação de que uma criança "sabe tudo sobre dinossauros" porque sabe o nome de alguns dinossauros mais mediáticos, é semelhante a saber o nome dos cromos de futebol, mas não se saber de que clube são, em que posição jogam, as regras, ou sequer saberem jogar futebol.

Mas a dificuldade de comunicar ciência a crianças não quer dizer que seja impossível. Um caso de sucesso foram os desenhos animados do Comboio dos Dinossauros ${ }^{2}$, onde uma família de Pteranodons adopta um T.rex. Nestes desenhos animados os jovens dinossauros andam num comboio de linha da era Mesozóica atravessando o túnel do tempo que para em três estações: o Triásico, o Jurássico e o Cretácico. Nas aventuras, estas personagens, que mimetizam crianças, vão conhecendo outros dinossauros e répteis mesozóicos aprendendo particularidades de cada animal e de cada período. No final de cada episódio um paleontólogo, Dr. Scott ${ }^{3}$, ainda responde a uma questão relacionada com o abordado anteriormente.

\section{Conclusão}

A comunicação da ciência para o público leigo, nomeadamente a paleontologia dos dinossauros, é um compromisso entre o fóssil puro original e a espetacularidade do dinossauro completo. E é um compromisso mais difícil de alcançar quando se tem em conta o público que faz mover os visitantes às exposições de dinossauros: crianças do primeiro ciclo. A equipa museográfica tem de saber gerir a precisão científica e a compreensão expositiva. Cabe ao museógrafo conseguir resumir que conceitos o paleontólogo acha imprescindível que estejam presentes. Como os transmitir da forma mais compreensível, e de preferência lúdica, sem perder precisão. Para isso o papel dos diversos agentes que constroem a exposição deve ser humilde nas competências dos seus pares, mas especializado nas suas próprias competências. Não cabe ao museógrafo saber o que transmitir assim como não cabe ao paleontólogo impor como transmitir. Cada vez mais, no caso da paleontologia assim como noutras ciências, deve almejar-se a especialização da museografia, e não

2. Dinosaur Train, é uma produção liderada pela The Jim Henson Company, dirigida por Craig Bartlett, de 2009, Americana, Canadiana e de Singapura.

3. Scott Sampson, é Canadiano douturado em Zoologia pela Universidade de Toronto, actualmente ocupando o cargo de "Vice President of Research \& Collections and Chief Curator" do Museu da Ciência e da Natureza de Denver. 
ocorrer, o que tantas vezes acontece, em que o cientista é especialista e consequentemente o discurso falha porque o responsável pela comunicação não o era.

\section{Bibliografia}

Barba, R.H. (1995). Children's Tacit and Explicit Understandings of Dinosaurs. Annual Meeting of the National Association of Research in Science Teaching, April: 2-14. San José. California.

Delicado, A. (2008). Produção e reprodução da ciência nos museus portugueses. Análise Social, XLIII(1): 55-77.

Gauthier, J. \& Queiroz, K. (2001). Feathered dinosaurs, flying dinosaurs, crow dinosaurs, and the name "Aves". In J. Gauthier \& L.F. Gall (eds.) New Perspectives on the Origin and Early Evolution of Birds: Proceedings of the International Symposium in Honor of John H. Ostrom. New Haven: Peabody Mus. Nat. Hist., Yale Univ.

Lapparent, A.F. \& Zbyszewski, G. (1957). Les Dinosauriens du Portugal. Memórias, Serv. Geol. Port., 2 (Nova série).

Leite, J. (2009). Contributo do Museu Nacional de História Natural para a divulçação do património Geológico: Caracterização do Público do Departamento de Mineralogia e Geologia. Tese de Mestrado pela Universidade do Minho.

Mateus, S. (2009). Qual o papel das réplicas museológicas?. Journal of Paleontological Techniques, Maio (6): 20-21. ISSN: 1646-5806.

Mateus, S. (2014). Fundamentos para uma exposição hipotética do Jurássico Superior da Lourinhã. Tese de Mestrado em Paleontologia, pela FCTUNL e UE.

Mateus, S.; Mateus, M. \& Faria, M.L. (2014). Público do Museu da Lourinhã, A procura dos dinossauros como paleopatrimónio. Atas / Proceedings I Encontro Luso-Brasileiro de Património Geomorfológico e Geoconservação: 82-88. ISBN: 978-989-96462-5-4.

Meiri, S. (2004). The Museology of Dinosaurs: in Search of the Authentic Museum Dinosaur. Tese de Doutoramento em Filosofia, pela University of Leicester. 
Exposições de Dinossauros em Portugal: Comunicar Paleontologia, Métodos e Problemáticas

Mitchell, W.J.T. (1998). The Last Dinosaur Book. The University of Chicago Press, Chicago.

Rieppel, L. (2012). Bring Dinosaurs Back to Life, Exhibiting Prehistory at the American Museum of Natural History. Isis, 103:460-490.

\section{Anexo}

\section{Cronologia das Exposições Temáticas de Dinossauros em Portugal}

1992 - "Dinossaurios Regressam a Lisboa" no Museu Nacional de História Natural e da Ciência em Lisboa (MUHNAC)

1994 - "Dinossauros ao vivo" no Jardim Zoológico de Lisboa.

2003 - Dinossauros da Mongólia, no Pavilhão Rosa Mota, no Porto.

2004 - Dinossauros de Gobi, Mongólia, na Torre Vasco da Gama, Lisboa.

2005 - "Plumas em Dinossáurios - Afinal nem Todos se Extinguiram" MUHNAC.

2010 - “Allosaurus: um dinossáurio, dois continentes?" - Exposição temporária de longa duração no MUHNAC.

2011/2012 - "O Mundo dos Dinossauros" em Lisboa na Cordoaria Nacional, em 2011, no Porto no Pavilhão Rosa Mota, em 2012, na Batalha na Exposalão, de 31 de Março a 3 de Junho de 2012, e em Portimão, no Parque de Feiras e Exposições, de 11 de Julho a 09 de Setembro de 2012.

2012/2013 - "T.rex: Quando as galinhas tinham dentes", no Pavilhão do Conhecimento, Lisboa.

2014 - "Planeta Dinossauro", no Pavilhão de Portugal, Lisboa. 